\title{
THE STEREOTYPES OF POLITICAL THINKING OF YOUTH IN THE CONTEXT OF NATIONAL SECURITY STRATEGY OF RUSSIA: EXPERIENCE OF REGIONAL RESEARCH
}

\author{
Vyacheslav N. Gulyaikhin \\ Volgograd Academy of the Ministry of Interior of the Russian Federation, Volgograd, Russian Federation
}

Olga E. Andryushchenko

Volgograd State University, Volgograd, Russian Federation

Pavel P. Fantrov

Volgograd State University, Volgograd, Russian Federation

Elena V. Galkina

North-Caucasus Federal University, Stavropol, Russian Federation

\begin{abstract}
The article evaluates the fundamental social factors which influence the formation of the axiological component of Russian youth's political consciousness. The authors have set a goal to find out to what extent the traditional moral and spiritual values are rooted in the minds of young people. These values need to be cultivated in accordance with the goals set in National Security Strategy of Russia, approved by the Decree of the President of the Russian Federation. Using the method of selective associations, the authors have identified the actual set of values, which form the stereotypes of political thinking of young citizens of the Volgograd region. It consists of such values $\infty$ as strong family, patriotism, strong state, love for neighbour, fortitude and faith. It's been found out that search for $\vec{\sim}$ truth and collectivism, which once were the fundamental values for the spiritual life of the Russian people, ceased to $\sim$ be so for the young generation of Russian citizens. The authors point to the revival of the dualism of the concepts of 펴 patriotism and pride, which was dominant in the public consciousness of the Soviet people. Nihilistic and protest moods are peculiar of only a small share of youth (no more than $3 \%$ ). Many traditional moral and spiritual values remain rooted in the political consciousness of young people in Volgograd, and this is a positive factor of national security in the region. The authors have concluded that despite a number of negative societal factors that have a - significant impact on the formation of value-semantic attitudes and stereotypes of political thinking of Russian youth, the traditional spiritual and moral values are still the important social regulators of political behavior.

V.N. Gulyaikhin describes the main traditional values of the Russian people and reveals a number of fundamental factors of public life that have a significant impact on the formation of values and stereotypes of the political thinking of Russian youth. E.V. Galkina gives an assessment of the ideological context of the document "The National Security is Strategy of the Russian Federation" and formulates the initial thesis about the need to view the youth as an active subject of the national security system. O.E. Andryushchenko develops a questionnaire for a mass survey of representatives of two age groups of young people, makes a sample for a mass questionnaire, and carries out an empirical study of the value-semantic attitudes and stereotypes of political thinking in the two main age groups of the Volgograd youth. P.P. Fantrov carried out a comparative analysis of stereotypes of thinking of these age groups.

Key words: political thinking, youth, national security, traditional values, Russia, Volgograd region, association, protest mood.

Citation. Gulyaikhin V.N., Andryushchenko O.E., Fantrov P.P., Galkina E.V. The Stereotypes of Political Thinking of Youth in the Context of National Security Strategy of Russia: Experience of Regional Research. Vestnik Volgogradskogo gosudarstvennogo universiteta. Seriya 4, Istoriya. Regionovedenie. Mezhdunarodnye otnosheniya [Science Journal of Volgograd State University. History. Area Studies. International Relations], 2018, vol. 23, no. 2, pp. 186-194. (in Russian). DOI: https://doi.org/10.15688/jvolsu4.2018.2.16
\end{abstract}




\title{
СТЕРЕОТИПЫ ПОЛИТИЧЕСКОГО МЫШЛЕНИЯ МОЛОДЕЖИ В КОНТЕКСТЕ РЕАЛИЗАЦИИ СТРАТЕГИИ НАЦИОНАЛЬНОЙ БЕЗОПАСНОСТИ РФ: ОПЫТ РЕГИОНАЛЬНОГО ИССЛЕДОВАНИЯ
}

\author{
Вячеслав Николаевич Гуляихин \\ Волгоградская академия МВД РФ, г. Волгоград, Российская Федерация
}

Ольга Евгеньевна Андрющенко

Волгоградский государственный университет, г. Волгоград, Российская Федерация

\section{Павел Петрович Фантров}

Волгоградский государственный университет, г. Волгоград, Российская Федерация

\section{Елена Вячеславовна Галкина}

Северо-Кавказский федеральный университет, г. Ставрополь, Российская Федерация

Аннотация. В статье дана оценка фундаментальных общественных факторов, оказывающих воздействие на формирование ценностного компонента политического сознания российской молодежи. Авторы поставили перед собой цель выяснить, насколько в сознании молодежи укоренены традиционные духовно-нравственные ценности, которые нужно культивировать в соответствии с задачами, поставленными в «Стратегии национальной безопасности России», утвержденной Указом Президента РФ. С помощью метода выборочных ассоциаций были определены аксиоланты, которые составляют основу стереотипов политического мышления молодых людей, проживающих в Волгоградской области. Выявлен реальный набор традиционных ценностей молодежи, который в качестве поведенческой установки оказывает воздействие на их политическое поведение. Его составляют такие ценности, как крепкая семья, патриотизм, сильное государство, любовь к ближнему, стойкость духа и веры. Установлено, что ранее считавшиеся основополагающими для духовной жизни русского народа ценностные установки «поиск правды» и «коллективизм» перестали быть таковыми для молодого поколения российских граждан. Можно констатировать, что произошел ренессанс дуализма концептов «патриотизм - гордость», который был доминирующим в общественном сознании советского народа. Нигилистические и протестные настроения присутствуют лишь у малой части молодежи (не более чем у 3 \%). Многие традиционные духовно-нравственные ценности остаются укорененными в политическом сознании волгоградской молодежи, что является позитивным фактором обеспечения национальной безопасности в регионе. Авторы пришли к выводу, что несмотря на наличие ряда негативных общественных факторов, оказывающих существенное воздействие на формирование ценностно-смысловых установок и стереотипов политического мышления российской молодежи, традиционные духовно-нравственные ценности продолжают выступать в качестве значимых социальных регуляторов ее политического поведения.

В.Н. Гуляихин выделил основные традиционные ценности российского народа и выявил ряд фундаментальных факторов общественной жизни, оказывающих существенное воздействие на формирование ценностно-смысловых установок и стереотипов политического мышления российской молодежи. Е.В. Галкина дала оценку идеологическому контексту документа «Стратегия национальной безопасности РФ» и сформулировала исходный тезис о необходимости рассматривать молодежь в качестве активного субъекта системы обеспечения национальной безопасности. О.Е. Андрющенко разработала анкету для массового опроса представителей двух возрастных групп молодежи, сделала проектирование выборки для массового анкетного опроса, после чего провела эмпирическое исследование ценностно-смысловых установок и стереотипов политического мышления двух основных возрастных групп волгоградской молодежи. П.П. Фантров осуществил компаративный анализ стереотипов мышления данных возрастных групп.

Ключевые слова: политическое мышление, молодежь, национальная безопасность, традиционные ценности, Россия, Волгоградская область, ассоциация, протестное настроение. 
Цитирование. Гуляихин В. Н., Андрющенко О. Е., Фантров П. П., Галкина Е. В. Стереотипы политического мышления молодежи в контексте реализации стратегии национальной безопасности РФ: опыт регионального исследования // Вестник Волгоградского государственного университета. Серия 4, История. Регионоведение. Международные отношения. - 2018. - Т. 23, № 2. - C. 186-194. - DOI: https://doi.org/10.15688/ jvolsu4.2018.2.16

В декабре 2015 г. указом Президента России была утверждена «Стратегия национальной безопасности РФ», в которой поставлена задача воспитания молодого поколения граждан на основе традиционных духовнонравственных и культурно-исторических ценностей. В документе понятие «молодежь» использовано всего два раза и исключительно в педагогическом контексте. Молодые люди признаны в качестве объекта воспитания, которое должно проводиться на основе традиционных моральных ценностей и с обязательной профилактикой экстремизма и политического радикализма.

В «Стратегии...» молодому человеку по сути отводится пассивная роль в деле противостояния внутренним и внешним угрозам российским национальным интересам. Он не рассматривается как активный субъект политической деятельности, направленной на поддержание национальной безопасности. Такой узкий взгляд на роль молодых людей в деле обеспечения национальной безопасности нельзя считать вполне оправданным. Тезисы о значимости традиционного духовнонравственного воспитания молодежи и необходимости профилактической работы с ней являются важной, но недостаточной составляющей Стратегии. Следует более активно использовать потенциал молодого поколения граждан в системе национальной безопасности России. О желании молодых людей более активно участвовать в решении общественно важных вопросов, связанных генетически также и с вопросами национальной безопасности, косвенно свидетельствует их участие в несогласованных со столичными властями акциях против коррупции в марте 2017 года.

Нельзя забывать и то, что экстремистские и террористические организации делают свою ставку прежде всего на молодых людей, как на наиболее активную часть населения. Манипуляторы различных политических оттенков предназначают им роль ударной силы, направленной против системы нацио- нальной безопасности. Из маргинальной молодежи пытаются сделать центробежную силу, способную разрушить российское государство, как когда-то был разрушен СССР. Из-за малого жизненного опыта и мировоззренческой дезориентации немалое количество молодых людей относительно легко поддаются манипулятивному воздействию со стороны как светских, так и религиозных ультрарадикальных идеологов. В этой связи показателен случай, происшедший со студенткой МГУ В. Карауловой, приговоренной судом за связь с террористической организацией ИГИЛ к четырем с половиной годам колонии общего режима.

Как известно, политическая социализация - это процесс, направленный на формирование как рациональных, так и ценностных компонент сознания личности, необходимых для ее адаптации к сложной политической системе общества. Традиционные ценности являются результатом сохранения памяти народа, имеющей как рациональные, так и иррационально-мифологические составляющие. Психологический стресс и такие его следствия, как страх, потеря первичных ценностей неизменно провоцируют иррациональное («магическое») мышление, которое далеко не всегда приводит к ложным суждениям [6, c. 78]. Каждому социуму требуется такой вид человеческой рациональности, который позволяет принимать правильные решения, даже если это трудно. Такая рациональность дает возможность рассуждать правильно, даже в условиях массированной неопределенности, она признает и в полной мере использует интуицию и эмоции, а не пытается отказаться от них [10, p. 224]. Традиционные ценности находят свое отражение в стереотипах политического мышления. Здесь возникает ряд вопросов. Насколько благоприятны внешние общественные условия для принятия гражданами в качестве социальных регуляторов традиционных духовно-нравственных ценностей. Какие аксиоланты следует признать традиционными и необходимыми для устойчивого по- 
литического развития российского социума, а не его стагнации? Является ли современная молодежь их носителем? Насколько сильны нигилизм и протестные настроения в молодежной среде?

Следует выделить целый ряд фундаментальных факторов общественной жизни, оказывающих существенное воздействие на формирование ценностно-смысловых установок и стереотипов политического мышления российской молодежи. К ним следует отнести:

- наличие противоречия между модернизационным требованием глобализации унифицировать национальные политические, правовые и этические системы на основе либеральных принципов (уважение частной собственности, гарантия прав и свобод личности, состязательность, равенство сторон перед законом и т. д.) и консервативными установками политической элиты на возрождение традиционных нравственных ценностей, национальную самобытность и укрепление духовных скреп российского социума;

- значительное замедление вертикальной социальной мобильности, консервирование политической элиты, ограничение доступа к власти активной молодежи, обладающей государственным и новаторским мышлением;

- насущная необходимость модернизации на демократических принципах общественно-политической системы с удалением из нее клептократических и кланово-сословных элементов;

- низкий уровень гражданского сознания и национально-государственного самосознания молодых людей, слабость позиции элемента «Я-россиянин» в их «Я-концепции», доминирование потребительских установок в социальном мышлении;

- стихийный характер политической социализации на фоне общей дегуманизации и деморализации российского общества, приводящей к мировоззренческой дезориентации значительной части молодежи;

- усиление ультрарадикальных идеологических воздействий на общественное сознание молодежи со стороны сетевых сообществ экстремистских и террористических организаций;

- стагнация экономики, монополизация хозяйственной жизни и отсутствие реальной рыночной конкуренции, приводящей к невостребованности креативного потенциала молодых российских граждан и их миграции как из экономически депрессивных регионов страны, так и из России;

- критическая социально-экономическая поляризация между высшими и низшими общественными группами населения, неудовлетворенность большей части молодежи своим общественным и экономическим положением;

- отсутствие значимых успехов в строительстве социального государства и слабая социальная защищенность молодых людей.

Среди исследователей не существует единого мнения по вопросу о содержании и истоках традиционных духовно-нравственных ценностей, сложившихся в российском социуме. Наиболее острые дискуссии идут между сторонниками светского и религиозного подходов к их определению. Отечественные мыслители чаще всего относят к числу традиционных ценностей державность (идею сильного государства и сильной централизованной власти), социальную справедливость (поиск правды), стойкость духа и веры, патриотизм, крепкую семью, сопереживание, милосердие и дружелюбие. В распоряжении правительства от 29 мая 2015 г. «Стратегия развития воспитания в Российской Федерации на период до 2025 года» появилась их официальная трактовка, не отличающаяся определенностью и конкретностью. В нем лишь декларируется, что «...воспитание детей на основе российских традиционных ценностей осуществляется за счет: развития у детей нравственных чувств (чести, долга, справедливости, милосердия и дружелюбия); формирования... способности к сознательному выбору добра; развития сопереживания и формирования позитивного отношения к людям...» [4]. В определении содержания традиционных нравственных ценностей более конкретен Президент РФ Владимир Путин. В январе 2015 г. на пленарном заседании Общероссийского форума «Государство и гражданское общество: сотрудничество во имя развития» он заявил: «Добровольчество, благотворительность, меценатство имеют в России глубокие корни, а чувство гражданского долга, патриотизм, доброта, милосердие всегда являлись нашими базовыми ценностями. И ничего с веками, сла- 


\section{ПОЛИТИЧЕСКИЕ НАУКИ И РЕГИОНОВЕДЕНИЕ}

ва богу, в этом смысле не меняется. Эти традиции нам нужно укреплять. Вижу в этом мощнейший ресурс развития России, консолидации общества, обеспечения социальной и межнациональной гармонии» [3].

В марте 2017 г. Научно-образовательным центром социальных технологий (НОЦСТ) Волгоградского государственного университета было проведено исследование проблем формирования ценностно-смысловых установок и стереотипов политического мышления двух основных возрастных групп волгоградской молодежи: 15-17 лет - время жизни, смежное с детством; 18-25 лет - время, пограничное со зрелостью. В ходе исследования была использована, во-первых, концепция М. Фридена о невозможности адекватной оценки политических идеологий без анализа всего спектра мыслительных практик политического мышления [7, p. 34]; во-вторых, методика спонтанных и выборочных ассоциаций Ш. Курильски-Ожвэн, занимающейся компаративистским анализом национальных моделей социализации молодежи [8].

Генеральной совокупностью исследования выступила вся учащаяся молодежь Волгоградской области. По данным Волгоградстата численность обучающихся в вузах на 01.012016 г. составляет 71,6 тыс. человек, ссузов - 39,2 тыс., общеобразовательных учреждений - 238 тыс. человек [2]. В качестве выборочной совокупности выступают обучающиеся вузов и ссузов дневной формы обучения, учащиеся 10-11 классов школ. Доверительный интервал исследования составляет 0,05 , доверительная вероятность - $95 \%$. При данных параметрах размер выборки должен составлять 400 человек. Объем респондентов составил 400 человек. Выборка репрезентирует молодое население (от 14 до 24 лет) по полу (юношей - $52 \%$, девушек $48 \%$ и уровню образования [9, p. 110]. Тип выборки - двуступенчатая, территориальная, случайная, гнездовая (район проживания в Волгоградской области, возраст). Погрешность не более 4,89\%. Было сформировано две подгруппы: группа студентов вузов $(n=200)$ и группа обучающихся ссузов и общеобразовательных учреждений $(n=200)$. Основной метод эмпирического исследования - анкетный опрос.
Адаптированная под российскую реальность методика выборочных ассоциаций М. Арутюнян и О. Здравомысловой позволила выявить ценностно-смысловые образы, являющиеся базовыми для политического мышления молодежи как субъектов традиционных ценностей $[9$, р. 38]. Ассоциации, вызванные понятиями «традиционные российские ценности», «Родина», «патриотизм» и «духовность», позволяют дать оценку молодежи как субъекту духовно-нравственных ценностей.

Социологический опрос показал, что с понятием «традиционные российские ценности» у младшей молодежной группы (15-17 лет) чаще всего связаны такие ассоциации, как «крепкая семья» $(14,33 \%)$, «державность (идея сильного государства)» $(14 \%)$ и «патриотизм» $(11,33 \%)$. Доминирование именно этих ценностей обусловлено тем, что семья и школа являются самыми влиятельными агентами политической социализации для юношеского возраста. Если семья культивирует свои «фамильные» ценности, то школа задает молодому человеку ценностные установки любви к Родине, служения Отечеству и патриотизма.

Усиление консервативных и эгоцентрических настроений потребительского общества способствовало тому, что ранее признаваемые за исконно русские ценности - «поиск правды» $(8 \%)$ и «коллективизм» $(6 \%)-$ заняли достаточно низкие приоритетные позиции. Культивируемая в современном обществе модернизационная установка на конкуренцию, персональный рост и карьерный успех делает устаревшими коллективистские ценности.

У старшей молодежной группы (1824 года) свой расклад в отношении к традиционным российским ценностям: на первом месте стоит патриотизм (13,66 \%), на втором - «любовь к ближнему, сопереживание, милосердие» $(13 \%)$ и на третьем - «стойкость духа и веры» (12\%). Здесь достаточно сильны религиозные мотивы- любовь, вера и дух. Экзистенциальный аксиолант, составляющий одну из духовных основ либерализма - «честь и достоинство личности», признали в качестве традиционного всего лишь $5 \%$ опрошенных молодых людей старшей группы.

В связи со сложной демографической ситуацией в российском обществе является нега- 
тивным то обстоятельство, что у старшей (репродуктивной) группы не вошли в тройку приоритетов семейные ценности $(9,33 \%)$. Это объясняется тем, что многие молодые люди вынуждены откладывать время вступления в брак на более поздний период из-за невозможности обеспечить семье достойное материальное существование. Этот фактор снизил уровень приоритетности семейных ценностей.

Нигилистическое отношение к традиционным российским ценностям проявляют около $10 \%$ молодежи. Так, «пьянство и воровство» за традиционную «ценность» признало лишь $4 \%$ младшей группы и 4,33 \% - старшей, а идеологему «добрый царь и плохие бояре» посчитали в качестве традиционной соответственно 4 и 6,33 \% молодых людей.

Ассоциации с понятием «Родина» не сильно разнятся у представителей молодежи разных возрастных групп. В тройку лидеров попали ассоциации «Россия», «место рождения» и «Отечество». Представители младшей группы данное понятие чаще связывают с малой Родиной - с местом рождения (17,66 \%) или родным для них городом Волгоградом (7,33\%). Большинство опрошенных продемонстрировали особенность политического мышления, отделяя понятие «Родина» от ассоциативного образа «государство». Об этом косвенно свидетельствует и то, что ассоциация «державность» появилась только у 3,66 \% младшей группы (еще меньше у старшей всего 2,33 \%), ассоциация «служить», близкая по смыслу к «державности», возникла у небольшой группы опрошенных - всего у 4,3 \% «младших» и 4 \% «старших».

Лишь для немногих молодых респондентов двух возрастных групп Родина ассоциируется с безопасностью (около $5 \%$ ) и справедливостью (2-3\%). Низкий уровень чувства безопасности у молодежи связан прежде всего с тем, что Волгоград неоднократно подвергался террористическим атакам, и среди их жертв было немало молодых людей. При сильной дифференциации в доходах населения и доминировании клановости в политической и социально-экономической сферах жизни региона волгоградской молодежи приходится лишь мечтать о социальной справедливости [1, с. 7]. Тем не менее в качестве положительного тренда эволюции общественного сознания следует отметить то, что ассоциация «эмиграция» при слове «Родина» возникает только у 2,3 \% молодых людей. Свое будущее молодежь связывает прежде всего с Россией.

Близкими у представителей двух возрастных групп молодых людей являются стереотипные ассоциации, связанные с термином «патриотизм». В тройку приоритетных ценностей здесь вошли «Родина» $(24,66$ и 22,66 \%), «гордость» $(15,66$ и 13,66 \%) и «Отечество» (13 и 15,66 \%). Можно говорить об определенном успехе государственных и общественных программ патриотического воспитания волгоградской молодежи: во-первых, в одном ценностно-смысловом ряду находятся концепты «патриотизм», «Родина», «гордость» и «Отечество»; во-вторых, нигилистические ассоциации, такие как «последнее прибежище негодяев» и «идиотизм», возникают менее, чем у $3 \%$ молодых людей, то есть укладываются в рамки статистической погрешности. Несмотря на все трудности общественного бытия, молодые люди испытывают гордость за свою Родину. В то же время «державность» - «государственный» концепт политического мышления - возникает лишь у 5-6 \% опрошенных молодых волгоградцев.

По отношению к концепту «духовность» лидирующие позиции заняли следующие ассоциации: у младшей возрастной группы «вера» $(21 \%)$, «душа» $(13 \%)$ и «великодушие» $(9,33 \%)$; у старшей - «вера» $(15,66 \%)$, «душа» $(12,66 \%)$ и «гармония» $(12,66 \%)$. В стереотипном восприятии духовности явно доминирует религиозный аспект. Следует отметить слабые ассоциативные связи данного концепта с «духовенством» $(3,33$ и $2,33 \%)$ и «школой» (3 и 1,66 \%), которые должны выступать главными производителями духовной продукции. По-видимому, выпадание духовности из ассоциативного ряда со школой и церковью является следствием того, что данные социальные институты слишком забюрократизировались и мало производят и воспроизводят духовного. Но не стоит принижать позитивную роль школы и церкви в воспитании молодежи. Ведь молодых нигилистов, признающих духовность всего лишь некой условностью, оказалось около $1 \%$.

Ответы на вопрос «Какие действия может предпринять гражданин, когда закон на- 
носит ему ущерб или противоречит его убеждениям?» позволили выявить не только наиболее авторитетные общественные и государственные организации, к которым готов обратиться за помощью молодой человек, но и определить уровень нигилизма и протестных настроений в молодежной среде. Наиболее популярные способы защиты своих прав, к которым готовы прибегнуть молодые люди, это обращение в правозащитные общественные организации (18,33 и $24 \%)$, суд (21 и $16 \%$ ) и прокуратуру (17,33 и $16 \%)$. И если у младшей группы лидирует суд, то у старшей - правозащитные организации, второе место по популярности заняли суд и прокуратура.

Наименее авторитетными оказались депутаты (4 и 3,65 \%). Скорее всего, это связано с системным невыполнением ими предвыборных обещаний и той нелицеприятной критикой, которая допускается СМИ в адрес отдельных представителей законодательной власти.

Немногие молодые люди готовы участвовать в радикальных акциях протеста, запрещенных властью (2 и 2,55 \%). Низкий уровень протестной активности волгоградской молодежи подтверждает малочисленность (около 800 человек) несанкционированного антикоррупционного митинга, состоявшегося 26 марта 2017 г., и относительно благодушный настрой его участников. Очевидец событий описывает характер молодежного протеста, приводя следующие факты: «Дойдя по верхней террасе набережной до храма Иоанна Предтечи, демонстранты неожиданно развернулись и двинулись в обратную сторону. Этот маневр сначала удивил, а потом, похоже, разозлил омоновцев - мало того, что серьезные мероприятия по обеспечению общественного порядка превратились в “догонялки”, так еще и пытающиеся настигнуть оппозиционеров правоохранители в итоге встроились в их задние ряды, чем вызвали шутки и смех не только среди протестующих, но и большого числа обывателей. "Полиция с народом! Охранители коррупционеров сменили ориентацию!"» [5].

Как способ решения проблемы с законом, выбрали эмиграцию $4 \%$ опрошенных представителей младшей группы волгоград- цев и $2,55 \%$ - старшей. Соответственно, можно сделать вывод, что такой вариант не является предпочтительным для подавляющего большинства молодежи. Политическую апатию и общественную пассивность демонстрирует также небольшое число респондентов. Ответ «Ничего не предпринимать. Все бесполезно» выбрали 2,67 \% младшей группы и $4,74 \%$ - старшей.

Таким образом, несмотря на наличие ряда негативных факторов (монополизация хозяйственной жизни и отсутствие здоровой конкуренции, снижение уровня жизни населения и наличие сильных клептократических кланов; когнитивный диссонанс национального самосознания из-за наличия глобального тренда на вестернизацию и слабость концепции «Я-россиянин» в политическом сознании граждан, вызванная неприятием концепта «россиянин» влиятельными субъектами политической социализации; политически несформированная национальная идея и мощный идеологический прессинг со стороны радикальных религиозных и светских организаций), оказывающих существенное воздействие на формирование ценностно-смысловых установок и стереотипов политического мышления молодежи, традиционные духовно-нравственные ценности продолжают выступать в качестве значимых социальных регуляторов поведения. Молодое поколение остается носителем таких значимых общественных ценностей, как крепкая семья, патриотизм, сильное государство, любовь к ближнему, стойкость духа и веры. Ранее считавшиеся основополагающими для духовной жизни русского народа ценностные установки на «поиск правды» и «коллективизм» перестали быть таковыми. Молодые люди связывают понятие «Родина» прежде всего со смысловым рядом «Россия», «место рождения» и «Отечество». У четверти опрошенных граждан господствуют ассоциации прежде всего с малой Родиной. Понятие «патриотизм» вызывает чаще всего такой ассоциативный ряд, как «Родина», «гордость» и «Отечество». Можно констатировать, что произошел ренессанс взаимосвязи концептов «патриотизм - гордость», который был доминирующим в общественном сознании советского народа. Нигилистические и протестные настроения присутствуют лишь у малой час- 
ти молодых людей - не более чем у $3 \%$. Учитывая непростую демографическую ситуацию в России, негативным является то, что старшая и наиболее репродуктивная группа молодежи не относит семейные ценности к приоритетным. Но в целом выявленные стереотипы социального мышления являются позитивным фактором сохранения политической стабильности и вполне укладываются в идеологический контекст Стратегии национальной безопасности РФ.

\section{СПИСОК ЛИТЕРАТУРЫ}

1. Бельских, И. Е. Кризис региональной экономики 2015-2017 гг. в России: поиск альтернатив развития / И. Е. Бельских // Региональная экономика: теория и практика. - 2014. - № 26. - С. 2-9.

2. Официальный сайт Волгоградстата. Электрон. текстовые дан. - Режим доступа: http:// volgastat.gks.ru/wps/wcm/connect/rosstat_ts/ volgastat/ru/statistics/sphere/(дата обращения: 18.03.2017). - Загл. с экрана.

3. Президент встретился с участниками форума, собравшим представителей НКО со всей России. - Электрон. текстовые дан. - Режим доступа: https://www.1tv.ru/news/2015-01-15/25208-prezident_ vstretilsya_s_uchastnikami_foruma_sobravshim _ predstaviteley_nko_so_vsey_rossii (дата обращения: 14.04.2017). - Загл. с экрана.

4. Распоряжение Правительства Российской Федерации от 29 мая 2015 г. № 996-р «Стратегия развития воспитания в Российской Федерации на период до 2025 года». - Электрон. текстовые дан. - Режим доступа: https://rg.ru/2015/06/08/vospitanie-dok.html (дата обращения: 14.04.2017). - Загл. с экрана.

5. С акциями 26 марта в Волгоград вернулся массовый уличный протест. - Электрон. текстовые дан. - Режим доступа: http://www.ng.ru/regions/201703-26/100_volgograd260317.html (дата обращения: 14.04.2017). - Загл. с экрана.

6. Старцев, Я. Ю. Феноменология иррационального в политическом мышлении и разнообразие логик политического действия / Я. Ю. Старцев // Научный ежегодник Института философии и права Уральского отделения Российской академии наук. -2015 . - Т. 15, № 4. - С. 67-106.

7. Freeden, M. The Political Theory of Political Thinking: The Anatomy of a Practice / M. Freeden. Oxford : Oxford University Press, 2013. - 345 p.

8. Kourilsky-Augeven, C. Legal Socialisation: From Compliance to Familiarisation through Permeation / C. Kourilsky-Augeven // European journal of legal studies. - 2007. - Issue 1. - April. - Electronic text data. - Mode of access: http://www.ejls.eu/current. php?id=1. - Title from screen.

9. Kourilsky-Augeven, C. Modele francais et modele russe de socialisation juridigue: la construction des attitudes a l'egard du Droit avant l'age adulte, Revue d'Etudes Comparatives Est-Ouest / C. KourilskyAugeven, O. Zdravomyslova, M. Arutjunjan. - Paris, 1994. - № 3 (Septembre). - P. 37-131.

10. Yudkowsky, E. Rationality: From AI to Zombies / E. Yudkowsky. - Berkeley: MIRI, 2015. - 1775 p.

\section{REFERENCES}

1. Belskih I.E. Krizis regionalnoy ekonomiki 2015-2017 gg. v Rossii: poisk alternativ razvitiya [Crisis of Regional Economy of 2015-2017 in Russia: Search for Development Alternatives]. Regionalnaya ekonomika: teoriya i praktika, 2014, no. 26, pp. 2-9.

2. Ofitsialnyiy sayt Volgogradstata [Official Website of Volgograd State Statistics Service]. URL: $\mathrm{http} / /$ volgastat.gks.ru/wps/wcm/connect/rosstat_ts/ volgastat/ru/statistics/sphere.

3. Prezident vstretilsya s uchastnikami foruma, sobravshim predstaviteley NKO so vsey Rossii [The President Met with the Participants of the Forum, Which Brought Together Representatives of NGOs from all over Russia]. URL: https://www.1tv.ru/news/ 2015-01-15/25208-prezident_vstretilsya_s_ uchastnikami_foruma_sobravshim_predstaviteley_nko_ so_vsey_rossii.

4. Rasporyazhenie Pravitelstva Rossiyskoy Federatsii ot 29 maya 2015 g. № 996-r «Strategiya razvitiya vospitaniya $v$ Rossiyskoy Federatsii na period do 2025 goda» [Order of the Government of the Russian Federation of May 29, 2015 no. 996-r "Strategy for Education Development in the Russian Federation for the Period Until 2025"]. URL: https:// rg.ru/2015/06/08/vospitanie-dok.html.

5. S aktsiyami 26 marta $v$ Volgograd vernulsya massovyy ulichnyy protest (2017) [The Rally of March 26, 2017 Provoked a Massive Street Protest in Volgograd]. URL: http://www.ng.ru/regions/2017-0326/100_volgograd260317.html.

6. Startsev Ya.Yu. Fenomenologiya irratsionalnogo v politicheskom myshlenii i raznoobrazie logik politicheskogo deystviya [Phenomenology of Irrational in Political Thinking and Diverse Logic of Political Action]. Nauchnyy ezhegodnik Instituta filosofii i prava Uralskogo otdeleniya Rossiyskoy akademii nauk [Scientific Year-Book of Institute of Philosophy and Law of the Ural Office of the Russian Academy of Sciences], 2015. no. 4, pp. 67-106.

7. Freeden M. The Political Theory of Political Thinking: The Anatomy of a Practice. Oxford, Oxford University Press, 2013. 345 p. 


\section{ПОЛИТИЧЕСКИЕ НАУКИ И РЕГИОНОВЕДЕНИЕ}

8. Kourilsky-Augeven C. Legal Socialisation: From Compliance to Familiarisation through Permeation. European journal of legal studies, 2007, no. 1. URL: http:// www.ejls.eu/current.php?id=1.

9. Kourilsky-Augeven Ch., Zdravomyslova O., Arutjunjan M. Modele francais et modele russe de socialisation juridigue: la construction des attitudes a l'egard du Droit avant l'age adulte. Revue d'Etudes Comparatives Est-Ouest, 1994, no. 3, pp. 37-131.

10. Yudkowsky E. Rationality: From AI to Zombies. Berkeley, MIRI, 2015. 1775 p. l'egard du Droit avant l'age adulte, Revue d'Etudes Comparatives EstOuest, 1994, no. 3, pp. 37-131.

\section{Information about the Authors}

Vyacheslav N. Gulyaikhin, Doctor of Sciences (Philosophy), Associate Professor, Professor of Department of Theory and History of State and Law, Volgograd Academy of the Ministry of Interior of the Russian Federation, Istoricheskaya St., 130, 400089 Volgograd, Russian Federation, gulyaich@yandex.ru, https://orcid.org/0000-0002-9077-4485

Olga E. Andryuschenko, Candidate of Sciences (Sociology), Associate Professor, Department of Social Work and Pedagogy, Volgograd State University, Prosp. Universitetsky, 100, 400062 Volgograd, Russian Federation, maimail@list.ru, https://orcid.org/0000-0003-4619-160X

Pavel P. Fantrov, Postgraduate Student, Department of Social Work and Pedagogy, Volgograd State University, Prosp. Universitetsky, 100, 400062 Volgograd, Russian Federation, pavelfantrov@rambler.ru, https://orcid.org/0000-0002-9832-6169

Elena V. Galkina, Doctor of Sciences (Politics), Professor, Department of Foreign History, Political Science and International Relations, North Caucasus Federal University, Pushkina St., 1, 355009 Stavropol, Russian Federation, galkina_e@mail.ru, https://orcid.org/0000-0003-0114-6012

\section{Информация об авторах}

Вячеслав Николаевич Гуляихин, доктор философских наук, доцент, профессор кафедры теории и истории права и государства, Волгоградская академия МВД РФ, ул. Историческая, 130, 400089 г. Волгоград, Российская Федерация, gulyaich@yandex.ru, https://orcid.org/0000-0002-9077-4485

Ольга Евгеньевна Андрющенко, кандидат социологических наук, доцент кафедры социальной работы и педагогики, Волгоградский государственный университет, просп. Университетский, 100, 400062 г. Волгоград, Российская Федерация, maimail@list.ru, https://orcid.org/0000-0003-4619-160X

Павел Петрович Фантров, аспирант кафедры социальной работы и педагогики, Волгоградский государственный университет, просп. Университетский, 100, 400062 г. Волгоград, Российская Федерация, pavelfantrov@rambler.ru, https://orcid.org/0000-0002-9832-6169

Елена Вячеславовна Галкина, доктор политических наук, профессор кафедры зарубежной истории, политологии и международных отношений, Северо-Кавказский федеральный университет, ул. Пушкина, 1, 355009 г. Ставрополь, Российская Федерация, galkina_e@mail.ru, https://orcid.org/0000-0003-0114-6012 